\title{
Geoelectric investigation of a proposed Mambilla Plateau Airport Runway, Taraba State, Nigeria
}

\author{
Omisore B.O., Olorunfemi M.O. \\ Department of Geology \\ Obafemi Awolowo University \\ Ile-Ife, Nigeria \\ olubusayoomisore@yahoo.com
}

\author{
Sheng Jin \\ School of Geophysics and Information \\ China University of Geosciences, Beijing \\ Beijing, China,
}

\begin{abstract}
Geoelectric investigation, involving electrical resistivity method, was carried out within a site earmarked for an airport runway in the Mambilla Plateau, Taraba State, Nigeria. The objective was to generate surface and subsurface geologic information required for the location and design of a stable airport runway. The data acquisition involved the Vertical Electrical Sounding (VES) which utilized Schlumberger array and 2-D subsurface imaging technique which utilized the dipoledipole array. 28 VES stations were occupied and 5 dipole-dipole profiles were traversed. The VES interpretation results were used to construct 3 Geoelectric sections and the isopach map of the lateritic (competent) layer. The dipole-dipole data were inverted to 2-D subsurface images using DIPRO Software. 4 lithologic layers were delineated. These included the topsoil, the lateritic hardpan, weathered basement and the fresh basement bedrock. The study concluded that the subsoils on or within which the proposed runway pavement would be founded were generally competent having both resistivity and thickness values that were higher than the established threshold of $1.5-2 \mathrm{~m}$ thickness of laterite and layer resistivity of $600 \mathrm{ohm}-\mathrm{m}$.
\end{abstract}

Keywords-geoelectric investigation; electrical resistivity method; 2-d subsurface imaging

\section{INTRODUCTION}

The stability of a pavement is determined by the soilsupport capabilities of the underlying subgrade which is the foundation of the pavement structure. Geophysical methods are applied in civil engineering construction related projects ranging from pre-construction feasibility study ${ }^{[1]}$ to post construction integrity assessment ${ }^{[2]}$. Since all civil engineering structures (e.g. roads, dams, buildings, runways, etc.) are founded on earth materials (soils/rocks), geophysics is applied to provide useful information regarding the early detection of potentially dangerous subsurface conditions ${ }^{[3]}$. Over the year: electrical resistivity methods have been substantially appliec in environmental and civil engineering ${ }^{[4]}$. Electrical methoa provides information which allow for the rapid characterization of subsurface formations, identification of th competent subsurface layer; and its thickness and dept] required for the design of civil engineering foundation ${ }^{[5]}$. The aim of this study was to generate surface and subsurface geologic information required for the location and design of stable airport runway and the objectives were to; delineate th subsurface lithological sequence, determine the geoelectric parameters, develop subsurface electrical images and bedrock relief; and establish information on the suitability of runway pavement design.

\section{FIELD SURVEY}

\section{A. Geology of the Study Area}

The study area is located on Mambilla Plateau in the eastern part of Taraba State, Nigeria. The terrain is generally undulating with its elevation ranging between 1719-1795 m above sea level. The area is considered as the northern continuation of Bamenda Highlands of Cameroon or Adamawa Highlands. Mambilla Plateau is underlain by Tertiary to Recent Volcanic rocks. The lithological units include; Basalts, Trachyte and Rhyolite ${ }^{[6]}$. Basalt which is the major rock type in the study area is highly weathered on most parts of the Plateau. This is believed to be as a result of the in situ chemical weathering that is common on the Plateau.

\section{B. Geophysical Acquisition}

The geophysical data acquisition involved the Vertical Electrical Sounding (VES) technique which utilized Schlumberger configuration and 2-D subsurface imaging technique which utilized the dipole dipole electrode array. The Schlumberger configuration was acquired with half current electrode spacing (AB/2) varied from 1 to $200 \mathrm{~m}$ with a maximum spread length of $400 \mathrm{~m}$. VES station interval was varied from 129 to $548 \mathrm{~m}$. In total 28 Schlumberger depths Sounding stations were occupied. The geoelectric parameters such as layer resistivities and their thicknesses were used to generate geoelectric sections. The dipole-dipole electrode configuration was utilized for the 2D subsurface imaging. Five dipole-dipole profiles were traversed, each $300 \mathrm{~m}$ long. The inter traverse separation was

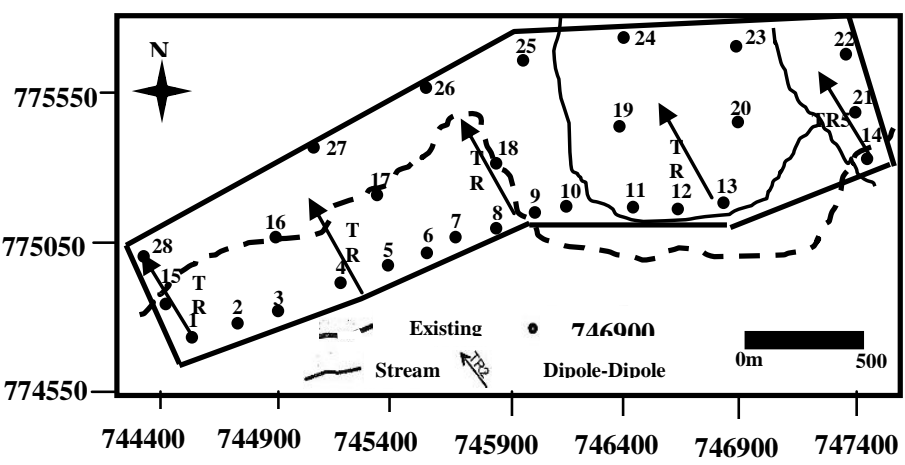

Fig. 1 Geophysical map of the study area 
$750 \mathrm{~m}$ and the profiles were oriented along Northwest Southeast direction (Fig. 1). Resistivity measurements were made at station interval of $10 \mathrm{~m}$ with an expansion factor (n), varying from $1-5$. The dipole - dipole data were inverted into 2-D resistivity structures and the results presented as pseudosections and resistivity structures. The PASI 16gL-N Digital Resistivity Meter was used for the acquisition of the geophysical data.

\section{RESULTS AND DISCUSSION}

\section{A. Vertical Electrical Sounding (VES) by Schlumberger Technigue}

The observed VES curves were interpreted quantitatively by partial curve matching and 1-D forward modeling using WinRESIST Software. The geoelectric parameters (layer resistivities and thicknesses) obtained from the interpretation models of VES data were used to construct the isopach map of the lateritic (competent) layer along three traverses (Fig. 2) and 2-D geoelectric sections beneath the study area (Fig. 3a-c). The interpretation results of these curves delineated 4 subsurface lithologic sequences beneath the study area which comprises: the topsoil (mainly lateritic), lateritic hard Pan, weathered basement and the fresh basement (bedrock).

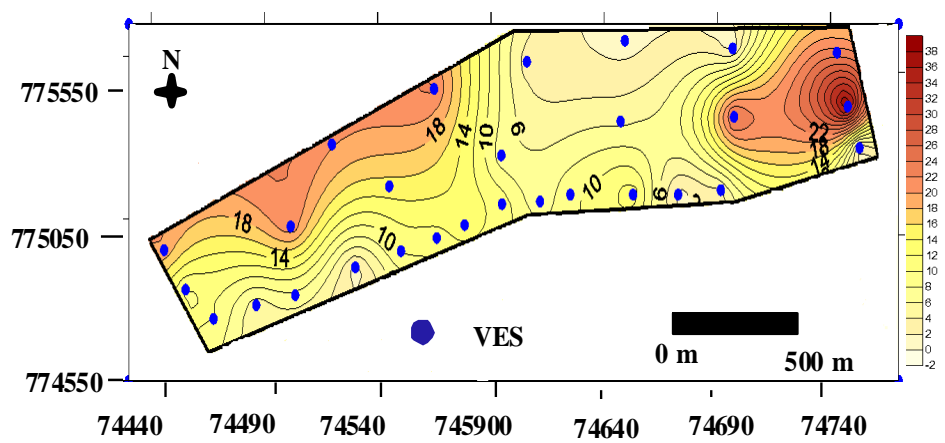

Fig. 2 Isopach map of the lateritic (competent) layer

The resistivity and thickness value of the topsoil layer varies from 1634 to $7081 \mathrm{ohm}-\mathrm{m}$ and 0.4 to $1.8 \mathrm{~m}$ respectively. The second layer is the lateritic hardpan with resistivity values and thicknesses varying from 600 to $44220 \mathrm{ohm}-\mathrm{m}$ and 0.3 and $24.9 \mathrm{~m}$ respectively. The third layer which is the weathered layer has layer resistivity value varying between 12 and 959 ohm-m and the thickness ranges from 4.2 to $94 \mathrm{~m}$. The last layer is the fresh basement with resistivity values ranging 1262 to $\infty$ ohm-m. The basement bedrock is encountered beneath all geoelectric sections at depths of between 0.6 and $116 \mathrm{~m}$. However, along Traverse 2, the fresh basement was undetermined except beneath VES 17 and 18.

\section{B. 2-D Resistivity Imaging Technique}

The dipole-dipole data were inverted to 2-D electrical images along 5 Traverses, using the DIPRO inversion Software. The 2-D resistivity structures revealed 3 subsurface lithologic sequences beneath the study area (Fig. 4a-c). The 1st two high resistivity layers in the geoelectric sections were merged into one in the $2-\mathrm{D}$ resistivity structures. The first layer is the resistive zone suggestive of the topsoil/lateritic layer in reddish color. This layer has resistivity values ranging from $1120-6025 \Omega \mathrm{m}$ and thickness varying between $5-30$ $\mathrm{m}$. The second layer is the weathered layer in bluish color. It has low resistivity values ranging from $37-500 \Omega \mathrm{m}$. The thickness of this layer was not mapped on most of the traverses except beneath traverse four with a thickness range of $5-25 \mathrm{~m}$. The third layer is the fresh basement bedrock in reddish- purple color. This high resistivity layer was not mapped beneath most of the traverses except beneath traverse 4 between stations 8 and 16 at the depth of about $27 \mathrm{~m}$. The $2-$ $\mathrm{D}$ resistivity technique imaged the subsurface stratigraphic sequence up to depth of $30 \mathrm{~m}$ (Table 1). Table 1 shows an estimate of laterite thickness of the study area derived from 2D images and the geo-electric sections.

(a)

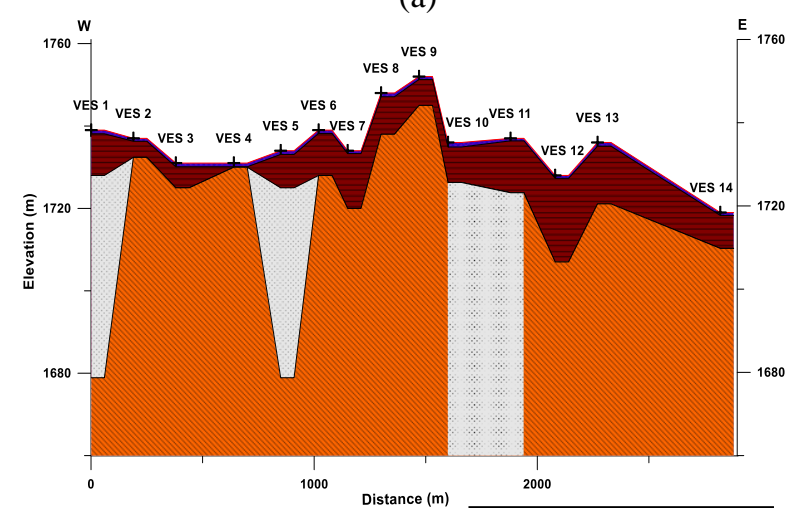

(b)

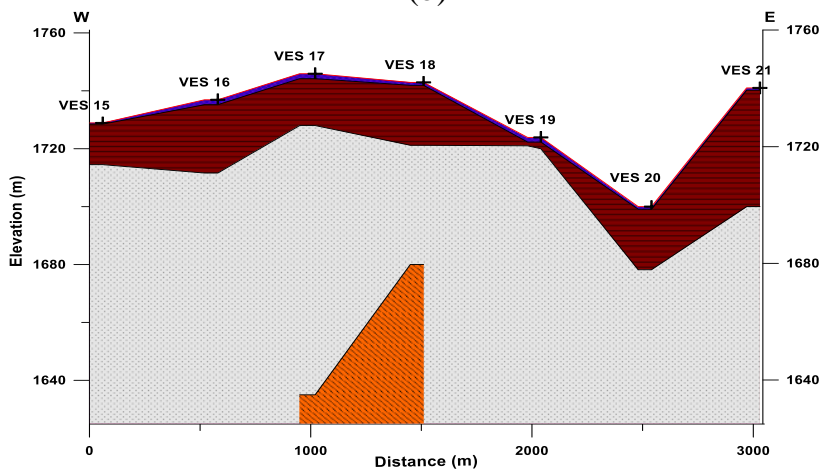

(c)

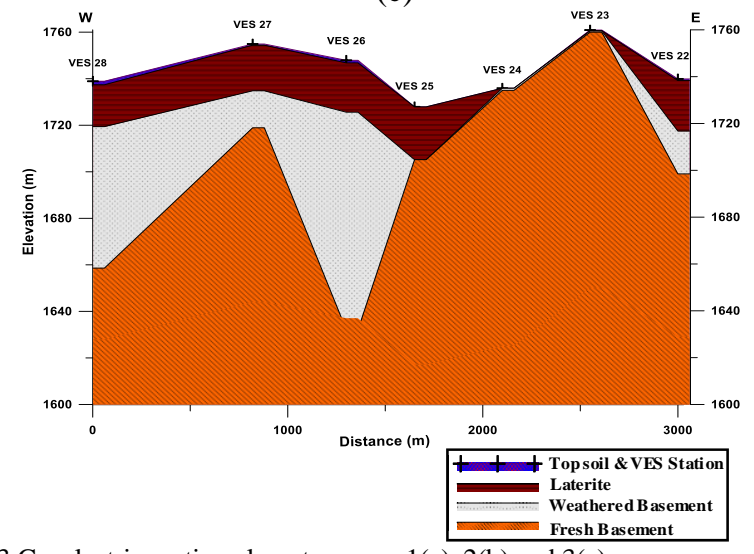

Fig. 3 Geoelectric section along traverses 1(a), 2(b) and 3(c) 


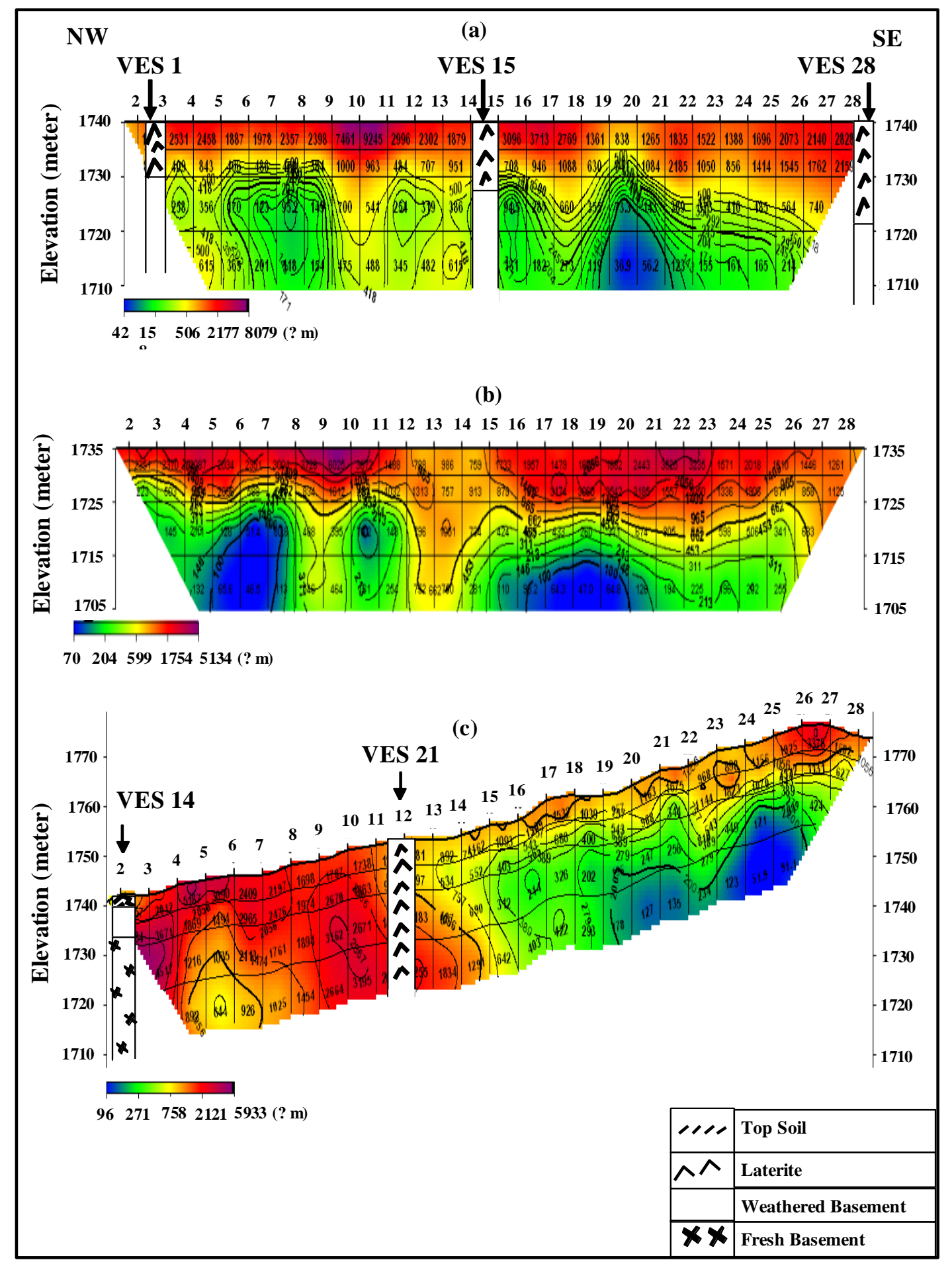

Fig. 4 a) Correlation of 2D resistivity inversion image with VES data along traverse 1, b) 2D resistivity inversion along traverse 2, c) Correlation of 2D resistivity inversion image with VES data along traverse 5 
TABLE I.

ESTIMATED LATERITE THICKNESS

\begin{tabular}{|l|l|c|c|}
\hline Location & Lithology & $\begin{array}{c}\text { Laterite } \\
\text { thickness } \\
\text { derived from } \\
2-D \text { inversion }\end{array}$ & $\begin{array}{c}\text { Laterite thickness } \\
\text { derived from } \\
\text { Geoelectric } \\
\text { sections }\end{array}$ \\
\hline Traverse 1 & Topsoil/Laterite & $5-20 \mathrm{~m}$ & $1.2-13.3 \mathrm{~m}$ \\
\hline Traverse 2 & Topsoil/Laterite & $5-15 \mathrm{~m}$ & $3.0-39.4 \mathrm{~m}$ \\
\hline Traverse 3 & Topsoli/Laterite & $5-20 \mathrm{~m}$ & $0.6-22.8 \mathrm{~m}$ \\
\hline Traverse 4 & Topsoil/Laterite & $3-5 \mathrm{~m}$ & - \\
\hline Traverse 5 & Topsoil/Laterite & $5->30 \mathrm{~m}$ & - \\
\hline
\end{tabular}

However, none of the 2-D images identified any potential settlement precipitating vertical or near vertical discontinuity such as fractures or faults. From the electrical resistivity surveys we observed that the study area is characterized by high resistivity topsoil which is lateritic in some places. This topsoil is virtually everywhere underlain by a higher resistivity lateritic hard pan whose average thickness is greater than $5 \mathrm{~m}$ (Fig. 3a-c and Fig. 4a-c) ${ }^{[7]}$. In his study established a threshold of $1.5-2 \mathrm{~m}$ of laterite as necessary to guarantee pavement stability. And we observed from geoelectric sections and 2-D images that the resistivity of each layer increases with depth. Therefore, there is an indication that the layer that will serve as the pavement subgrade is competent.

\section{CONCLUSION}

The topsoil is in most places underlain by a higher resistivity lateritic hardpan. The increase in layer resistivity with depth is an indication of an increasing subsoil competence. We identified the subsoil which is the combination of topsoil and laterite as the competent subgrade layer in the study area. The competent topsoil/laterite hardpan has thicknesses ranging from $0.6-39.4 \mathrm{~m}$ from geo-electric sections and $3-30 \mathrm{~m}$ from 2-D images (Fig.4a-c and Fig. 3ac). All the determined geotechnical parameters (resistivity and thickness of competent layer) of the subsoil fall within the specification recommended by ${ }^{[7]}$ required to guarantee pavement stability such as a threshold of laterite thickness and resistivity values of $1.5-2 \mathrm{~m}$ and $600 \mathrm{ohm}-\mathrm{m}$ respectively. It can therefore be concluded that, the subsoil on or within which engineering structures will be founded within the study area are generally competent. However, the rugged terrain of the survey area, as reflected in the geo-electric sections (Fig. 3a-c), will necessitate significant cut in some parts of the study area to achieve a flat terrain required for a runway. And this may lead to the eventually placement of such parts of the runway pavement on low resistivity, incompetent clayey weathered layer with the attendant pavement failure precipitating tendency.

\section{ACKNOWLEDGMENT}

We specially appreciate GEOTEC Nigeria for proving us with the data sued in this study.

\section{REFERENCES}

[1] R. Luna, aand H. Jadi, "Determination of dynamic soil properties using Geophysical Methods". Proc. First Int. Conf. on the Application of Geophysical and NDT methodologies to Transportation Facilities and Infrastructure Geophysics (federal highway administration, Saint Loius, MO) vol.3, pp.1-15, 2000.

[2] S. Bayode, G. O. Omosuyi, and H. I. Abdullai, "Post-foundation Engineering Geophysical Investigation in part of the Federal University of Technology, Akure, Southwestern Nigeria". Journal of Emerging Trends in Engineering and Applied Sciences (JETEAS), vol. 3 (1), pp. 203-210, 2012.

[3] S. Bayode, G. O. Omosuyi, and H. I. Abdullai, "Post-foundation Engineering Geophysical Investigation in part of the Federal University of Technology, Akure, Southwestern Nigeria". Journal of Emerging Trends in Engineering and Applied Sciences (JETEAS), vol. 3 (1), pp. 203-210, 2012.

[4] P. M. Soupios, P. Georgakopoulos, N. Papadopoulos, V. Saltas, A. Andreadakis, F. Vallianatos, A. Sarris, and J P. Makris, "Use of Engineering Geophysics to Investigate a Site for a Building Foundation". Journal of Geophysics Engineering, vol.4, pp.1, 2007.

[5] I. A. Adeyemo, "Application of Electrical Resistivity method in investigation of causes of Road failure Along Ilesha-Akure-Benin Federal Highway". International Journal of Engineering Research and Applications (IJERA) vol. 4 (8), pp. 443-454, 2004.

[6] GSD, "Geological Map of Nigeria". Geological Survey Department, Ministry of Mines, Power and Steel, Nigeria; 1:500,000, 2006.

[7] J. O. Fatoba, "Geoelectric, Geotechnical and Remote Sensing Investigation of Flexible Highway Pavement Failure along Shagamu Benin Expressway, South western, Nigeria". Unpublished PhD. Thesis, Obafemi Awolowo University, Ile-Ife, 2012. 